\title{
Chronic lymphocytic leukaemia: clinical-aetiological findings in 66 patients and their families
}

\author{
Walter Weber', Patrick F. Maurer², Jacqueline Estoppey', Marcel Zwahlen ${ }^{3}$ \\ IClinical Cancer Etiology Unit, Heuberg 16, CH-4051 Basel, Switzerland \\ 2Urological University Clinic of Both Basel, CH-4410 Liestal, Switzerland \\ 3ISPM, University of Bern, CH-3012 Bern, Switzerland
}

Key words: CLL, chronic lymphocytic leukaemia, familial leukaemia, familial cancer

Corresponding author: Walter Weber, Medical Oncology, Heuberg 16, CH-4051 Basel, Switzerland, phone: +41 0612610225 , fax: +410612618009,e-mail: cancer@bluewin.ch

Submitted: 2 August 2007

Accepted: 30 September 2007

\begin{abstract}
Background: Little is known about the aetiology of chronic lymphocytic leukaemia (CLL). The family medical history is a "genomic tool" capturing interactions of genetic susceptibility, shared environment and common behaviours. Methods: A cohort of 66 consecutives patients with CLL (probands) was studied in a medical oncology practice (W.W.) from 1981 until 2005. A German version of the $\mathrm{NCl}$ medical history questionnaire for cancer aetiology was used. Familial clustering analysis was done by comparing the proportion of specific tumours in the first degree relatives of the CLL practice cohort with corresponding proportions of population-based cancer registry data.

Results: 18 (41\%) male and 5 (23\%) female CLL probands had multiple malignancies, e.g. 2 meningiomas, 7 and 19 years after diagnosis of CLL. 46 (12\%) first degree relatives had malignancies with an excess of CLL. Other conspicuous familial associations are CLL with malignancies of the upper GI tract (oesophagus, stomach) and of the nervous system.

Conclusions: 1. Chronic lymphocytic leukaemia clusters in some families like any other disease. Predisposition genes should be searched. 2. Cancer prevention and early detection should be continued in CLL patients because of their longevity and high risk for multiple malignancies. 3. The overrepresentation of upper $\mathrm{Gl}$ malignancies in first degree relatives of CLL patients calls for targeted oesophago-gastroscopy screening studies.
\end{abstract}

\section{Introduction}

Every human disease clusters in families to some extent. This is also true for cancer. All sites show an excess of cancers of the same site among relatives, with thyroid and colon cancers and lymphocytic leukaemia showing the highest familial risks [1]. There is also familial clustering of malignancies originating from different primary sites [2].

Taking the family history of cancer patients is a low technology approach which can be applied all over the world [3]. It is a tool to identify high risk persons and families and to down-stage disease by targeted prevention and therapeutic approaches [4].

The family medical history represents a "genomic tool" that can capture interactions of genetic susceptibility, shared environment, and common behaviours in relation to disease risk [5]. It is well suited to research into cancer aetiology, of which little is known in chronic lymphocytic leukaemia (CLL), the most common form of leukaemia [6]. 
To gain aetiological clues a cancer-related family history in a private oncology practice cohort of 66 subsequent CLL patients has been evaluated.

\section{Materials and methods}

A cohort of 66 consecutive patients with CLL was studied in a medical oncology practice (W.W.) from 1981 until 2005.

The diagnoses of CLL were made by standard clinical, haematological and immunological criteria. The family history was elicited with a German version of the $\mathrm{NCl}$ medical history questionnaire for cancer aetiology [7]. The anamnestic data were verified as far as possible by obtaining copies of medical and pathology reports. Every pedigree was carefully examined for aetiological clues. In addition familial clustering analyses was made by comparing the proportion of specific tumours among all diagnosed tumours in the first degree relatives (FDR) of

Table 1. Multiple primaries in 23 patients with CLL

\begin{tabular}{|c|c|c|c|}
\hline First primary & Second primary & $\begin{array}{l}\text { Third } \\
\text { primary }\end{array}$ & N. pat. \\
\hline \multicolumn{4}{|l|}{ Male } \\
\hline CLL & lung & & 3 \\
\hline CLL & liver & & 1 \\
\hline CLL & skin (spinalioma) & & 1 \\
\hline CLL & prostate & & 1 \\
\hline CLL & bladder & & 1 \\
\hline CLL & meningioma & & 1 \\
\hline Prostate & $\mathrm{CLL}$ & & 3 \\
\hline $\begin{array}{l}\text { Skin (melanoma, } \\
\text { sweat gland) }\end{array}$ & $\mathrm{CLL}$ & & 2 \\
\hline Skin (basalioma) & CLL & oesophagus & 1 \\
\hline Skin (basalioma) & $\mathrm{CLL}$ & prostate & 1 \\
\hline Liposarcoma & $\mathrm{CLL}$ & & 1 \\
\hline Kidney & $\mathrm{CLL}$ & & 1 \\
\hline Bladder & $\mathrm{CLL}$ & & 1 \\
\hline \multicolumn{4}{|l|}{ Female } \\
\hline $\mathrm{CLL}$ & anus & & 1 \\
\hline CLL & kidney & & 1 \\
\hline CLL & meningioma & & 1 \\
\hline $\mathrm{CLL}$ & $\begin{array}{l}\text { essential } \\
\text { thrombocythaemia }\end{array}$ & anus & 1 \\
\hline OMF & $\mathrm{CLL}$ & & 1 \\
\hline
\end{tabular}

the probands with corresponding proportions of incidence data of the years 1981 and 1982 in the population of Geneva, Switzerland and of the years 1983-1987 in the population of Basel, Switzerland [8, 9].

\section{Results}

\section{CLL patients (probands)}

The 66 probands were 44 male (median age: 67 years; range 39 years to 85 years) and 22 female (median age: 65 years; range 38 years to 88 years). The age distribution of the probands corresponds to the age distribution of patients in the general population (Kolmogoroff-Smirnoff-test).

47 (71\%) CLL were typed immunologically: 46 had B-CLL and 1 had T-CLL. 18 male patients (41\%) and 5 female patients $(23 \%)$ had multiple malignancies (Table 1).

Table 2. Malignancies in 46 first degree relatives

\begin{tabular}{|c|c|c|c|}
\hline Cancer site & Male & Female & Total \\
\hline Uncertain & 3 & 3 & $6^{*}$ \\
\hline CLL & 2 & 3 & $5^{*}$ \\
\hline Breast & 0 & 4 & 4 \\
\hline Stomach & 2 & 2 & 4 \\
\hline Oesophagus & 3 & 0 & $3^{*}$ \\
\hline Colorectum & 3 & 0 & 3 \\
\hline Lung & 3 & 0 & 3 \\
\hline Brain & 3 & 0 & $3^{*}$ \\
\hline Leukaemia & 0 & 3 & $3^{*}$ \\
\hline Skin & 0 & 2 & 2 \\
\hline ENT & 1 & 0 & 1 \\
\hline Liver & 1 & 0 & 1 \\
\hline C. tissue & 1 & 0 & 1 \\
\hline Larynx & 1 & 0 & 1 \\
\hline Prostate & 1 & & 1 \\
\hline Cervix & & 1 & 1 \\
\hline Ovary & & 1 & 1 \\
\hline Thyroid & 1 & 0 & 1 \\
\hline $\mathrm{NHL}$ & 1 & 0 & 1 \\
\hline Myeloma & 1 & 0 & 1 \\
\hline Other & 0 & 0 & 0 \\
\hline Total & 27 & 19 & 46 \\
\hline
\end{tabular}




\section{First degree relatives (FDR)}

46 (12\%) of the 372 FDR had malignancies. There was a significant excess of CLL, other leukaemias, and of malignancies of uncertain origin, of oesophagus and brain (Table 2).

In 5 families (8\%) CLL occurred in relatives. Affected were mother and sister in one family, fathers in two families, mother and sister in one family each.

\section{Discussion}

\section{CLL patients}

The CLL patients frequently had multiple primary cancers, confirming previous reports [10]. In our study there is male dominance and CLL is associated with malignancies of the skin, prostate, lung, urinary tract, anus, meninges and bone marrow (myeloproliferative diseases). The observed/expected ratio was 1.20 (95\% confidence interval: 1.15-1.26) in a population-based US study [11].

Cancer prevention and early detection should be continued in CLL patients because of their longevity and high risk for second malignancies. These should be treated as they would be in patients without CLL [12].

\section{Families of CLL patients}

CLL clusters in some families like any other disease [13]. The transmission pattern suggests a dominant model of heredity [14]. Inherited predisposition to CLL is detectable as subclinical monoclonal B-lymphocyte expansion [15].

Gains and losses in two regions of the $X$ chromosome, Xp1 1.2-p21 and Xq21-qter, appear more common in familial CLL than in sporadic CLL [16]. Another candidate region is on chromosome 13 [17].

Predisposition genes should be searched. Serum $B$-lymphocyte stimulator (BlyS) levels are elevated in patients with familial B-CLL [18]. Elevated BLyS levels correlate with the presence of a T at -871 in the BLyS promoter [18].

In our study oesophageal and brain cancers were overrepresented in male first degree relatives. There were also 4 stomach cancers, not reaching statistical significance. In Bulgaria stomach cancer was particularly often diagnosed in families of CLL patients [19]. In addition one of our CLL patients (woman, 40-years-old at diagnosis) had a brother with duodenal gastrointestinal stomach tumour (GIST) at age 36. The frequent occurrence of upper $\mathrm{Gl}$ malignancies in FDR of CLL patients calls for targeted oesophago-gastroduodenoscopy screening studies.

\section{References}

1. Goldgar DE, Easton DF, Cannon-Albright LA, Skolnick MH. Systematic population-based assessment of cancer risk in firstdegree relatives of cancer probands. J Natl Cancer Inst 1994; 86: 1600-1008.

2. Hemminki K, Vaittinen P. National database of familial cancer in Sweden. Genet Epidemiol 1998; 15: 225-236.

3. Weber W, Estoppey J, Stoll H. Familial cancer diagnosis. Anticancer Res 2001; 21: 3631-3636.

4. Emery J, Murphy M, Lucassen A. Hereditary cancer - the evidence for current recommended management. Lancet Oncol 2000; 1: 9-16.

5. Yoon PW, Scheuner MT, Khoury MJ. Research priorities for evaluating family history in the prevention of common chronic diseases. Am J Prev Med 2003; 24: 128-135.

6. Chiorazzi N, Rai KR, Ferrarini M. Chronic lymphocytic leukemia. N Engl J Med 2005; 352: 804-815.

7. Mulvihill JJ, Miller RW, Fraumeni JF Jr (eds). Genetics of Human Cancer. Raven Press, New York 1977; 489-493.

8. Muir C, Waterhouse J, Mach T, Powell J, Whelan S (eds). Cancer Incidence in Five Continents. Volume III, IARC, Lyon 1976; 374-375.

9. Parkin DM, Muir CC, Whelan SL, Gao YT, Terlay J, Powell J. Cancer Incidence in Five Continents. Volume VI, IARC, Lyon 1992; 748-749.

10. Greene $M H$ and Wilson J. Second cancer following lymphatic and hematopoietic cancers in Connecticut, 1935-82. Natl Cancer Inst Monogr 1985; 68: 191-217.

11. Hisada M, Biggar RJ, Greene MH, Fraumeni JF Jr, Travis LB. Solid tumors after chronic lymphocytic leukemia. Blood 2001; 98: 1979-1981.

12. Wiernik PH. Second neoplasms in patients with chronic lymphocytic leukemia. Curr Treat Options Oncol 2004; 5: 215-223.

13. Yuille MR, Matutes E, Marossy A, Hilditch B, Catovsky D, Houlston RS. Familial chronic lymphocytic leukemia: a survey and review of published studies. Br J Haematol 2000; 109: 794-799.

14. Casey R, Brennan P, Becker N, Boffetta P, Cocco P, DomingoDomenech E, Foretova L, Nieters A, de Sanjose S, Staines A, Vornanen M, Maynadie M. Influence of familial cancer history on lymphoid neoplasms risk validated in the large European casecontrol study epilymph. Eur J Cancer 2006; 42: 2570-2576.

15. Rawstron AC, Yuille MR, Fuller J, Cullen M, Kennedy B, Richards SJ, Jack AS, Matutes E, Catovsky D, Hillmen P, Houston RS. Inherited predisposition to CLL is detectable as subclinical monoclonal B-lymphocyte expansion. Blood 2002; 100: 2289-2291.

16. Summersgill B, Thornton P, Atkinson S, Matutes E, Shipley J, Catovsky D, Houlston RS, Yuille MR. Chromosomal imbalances in familial chronic lymphocytic leukemia: a comparative genomic hybridisation analysis. Leukemia 2002; 16: 1229-1232.

17. Ng D, Toure O, Wei MH, Arthur DC, Abbasi F, Fontaine I, Marti GE, Fraumeni JF Jr, Goldin LR, Caporaso N, Toro JR. Identification of a novel chromosome region, 13q21.33-q22.2, for susceptibility genes in familial chronic lymphocytic leukemia. Blood 2007; 109: 916 -925.

18. Novak AJ, Grote DM, Ziesmer SC, Kline MP, Manske MK, Slager S, Witzig TE, Shanafelt T, Call TG, Kay NE, et al. Elevated serum B-lymphocyte stimulator levels in patients with familial lympho-proliferative disorders. J Clin Oncol 2006; 24: 983-987.

19. Nenova IS, Karnolski IN, Mateva NG, Sotirova KN. Familial study of chronic lymphocytic leukemia: aggregation of different malignant processes in families with individuals affected with chronic lymphocytic leukemia. Folia Med (Plovdiv) 2006; 48: 11-16. 